\title{
Deteksi Dini Perkembangan Anak dengan DDST (Denver Development Screening Test) di RA/KBIT Siti Khodijah Slawi
}

\author{
Anisa Oktiawati ${ }^{1}$, Ita Nur Itsna ${ }^{2}$, Ramadhan Putra Satria ${ }^{3}$, Jumrotun Ni'mah ${ }^{4}$ \\ STIKES Bhakti Mandala Husada Slawi, Jalan Cut Nyak Dien No.16, Kalisapu, Slawi, Kalisapu, \\ Kec. Slawi, Tegal, Jawa Tengah 52416 \\ Email: rajendraadhyazkawidodo@gmail.com
}

\begin{abstract}
ABSTRAK
Latar belakang: Masa balita merupakan pertumbuhan dasar yang akan mempengaruhi dan menentukan perkembangan anak selanjutnya. Pada usia ini otak anak mengalami pertumbuhan yang sangat pesat yang dikenal dengan istilah Masa Emas (The Golden Age). Golden age merupakan masa yang sangat penting untuk memperhatikan tumbuh kembang anak secara cermat agar sedini mungkindapat terdeteksi apabila terjadi kelainan. Berdasarkan data yang diperoleh di RA/KBIT Siti Khodijah Slawi terdapat 24 siswa yang berusia 3-4 tahun, 67 siswa yang berusia 4-5 tahun dan 91 siswa yang berusia 5-6 tahun. Tujuan: Meningkatkan pengetahuan guru tentang pemantauan perkembangan pada anak, Memberikan edukasi tentang metode skrining perkembangan anak dengan metode DDST, Melakukan pemantauan perkembangan terhadap anak dengan metode DDST. Metode: Pelaksanaan pengabdian masyarakat dengan menggunakan pengukuran DDST (Denver Development Screening Test) di RA/KBIT Siti Khodijah Slawi dilaksanakan pada hari Selasa, Tanggal 25 Februari 2020. Hasil: Hasil Pemeriksaan DDST yang dilakukan pada 125 anak didapatkan hasil keseluruhan adalah 121 anak (96,8\%) dinyatakan normal, 3 anak $(2,4 \%)$ mengalami perkembangan suspect dan 1 anak $(0,8 \%)$ tidak dapat dites. Tumbuh kembang anak secara menyeluruh dapat diamati dari gerak kasar (motorik kasar), gerak halus (motorik halus), kemampuan bicara, bahasa, bersosialisasi, kemandirian. Kesimpulan: Dengan adanya guru RB/KB IT yang terlatih diharapkan kegiatan deteksi dini perkembangan anak dapat berjalan secara rutin sehingga perkembangan anak menjadi tanggung jawab bersama antara orang tua dan guru. Guru diharapkan dapat memperhatikan perkembangan anak didiknya dengan cara menstimulasi pada 4 aspek perkembangan, yaitu personal sosial, adaptif-motorik halus, bahasa, dan motorik kasar agar perkembangan anak dapat mencapai optimal.
\end{abstract}

Kata Kunci: Anak; DDST; Perkembangan

\begin{abstract}
Background: Childhood is a basic growth that will influence and determine the child's subsequent development. At this age, the child's brain experiences very rapid growth known as the Golden Age. The Golden age is a very important time to pay close attention to the child's growth and development so that as early as possible, it can be detected if abnormalities occur. Based on data obtained at RA/KBIT Siti Khodijah Slawi, there were 24 students aged 3-4 years, 67 students aged 4-5 years and 91 students aged 5-6 years. Objective: The socialization can improve teacher knowledge about monitoring the children development, provide education about screening methods by DDST method, and conduct monitoring the development of children with the DDST method. Method: Implementation of community service use Detection of Child Development with DDST (Denver Development Screening Test) scale at RA/KBIT Siti Khodijah Slawi was held on Tuesday, February 25, 2020. Results: Results of DDST examination conducted on 125 children showed that overall results were 121 children (96.8\%) declared normal, 3 children (2.4\%) experienced development suspect, and one child (0.8\%) could not be tested. The whole child development can be observed from gross motion, fine motion, speech ability, language, socializing, and their independence. Conclusion: With the presence of RB/KB IT teachers, it is expected that early detection of the children development activities can be carried out routinely so that it is a shared responsibility between parents and teachers. Teachers are expected to pay attention to the students' development by stimulating 4
\end{abstract}


aspects of development, namely personal social, adaptive-fine motor, language, and gross motor skills so that children's development can reach optimal levels.

Keywords: Children, DDST, Development

\section{PENDAHULUAN}

Masa balita merupakan periode pertumbuhan dasar yang dapat mempengaruhi dan menentukan perkembangan anak selanjutnya. Pada usia ini otak anak mengalami perkembangan yang sangat pesat yang dikenal dengan istilah Masa Emas (The Golden Age). Golden age merupakan dimana periode yang sangat penting untuk memperhatikan tumbuh kembang anak secara cermat supaya lebih awal dapat mendeteksi apabila terjadi kelainan. Pemantauan tersebut harus dilakukan secara teratur dan berkelanjutan (Chamidah, 2009).

Data Riskesdas tahun 2013 gangguan pertumbuhan pada anak balita di Indonesia mencapai 35,7\%. Gangguan tumbuh kembang anak dapat dikendalikan sejak awal, tergantung kepada orang tua dalam memberikan stimulasi pada anak. Salah satu metode untuk mendeteksi kelainan perkembangan anak yaitu dengan Denver Development Screening Test (DDST). DDST bukan termasuk dalam tes diagnostik atau tes IQ. DDST memenuhi semua persyaratan yang diperlukan untuk metode skrining yang baik. Tes ini mudah dan cepat dalam penggunaannya (15-20 menit), dapat diandalkan serta menunjukkan validitas yang tinggi. Penilaian DDST ini menilai perkembangan anak dalam empat sektor, yang meliputi penilaian personal sosial, motorik halus, bahasa, dan motorik kasar (Soetjiningsih \& Ranuh, 2012).

Berdasarkan data yang diperoleh di RA/KBIT Siti Khodijah Slawi terdapat 24 siswa yang berusia 3-4 tahun, 67 siswa yang berusia 4-5 tahun dan 91 siswa yang berusia 5-6 tahun. Hasil studi pendahuluan didapatkan fakta bahwa para guru belum memahami secara maksimal penerapan metode skrining perkembangan anak dengan DDST (Denver Development Screening Test). Dengan demikian perlu adanya upaya penyuluhan atau sosialisasi kepada guru tentang metode skrining pemantauan perkembangan anak dengan DDST sekaligus pemantauan langsung terhadap perkembangan pada anak yang berada di TK tersebut.

Permasalahan mitra adalah belum adanya sosialisasi pada guru untuk melakukan pemantauan perkembangan dengan menggunakan metode DDST. Perlu adanya pemantauan DDST secara langsung pada anak yang berada di RB/KBIT Siti Khodijah untuk mengetahui perkembangan anak sesuai dengan tahapan usianya. Untuk mengatasi 
permasalahan di atas, maka sebagai bentuk tanggung jawab dosen dalam melaksanakan tridarma perguruan tinggi perlu diadakan sosialisasi yang bertujuan untuk meningkatkan pengetahuan guru tentang deteksi dini dan pemantauan perkembangan anak dengan DDST. Berdasarkan berbagai kajian masalah yang dihadapi mitra pada bagian sebelumnya, maka pemberian penyuluhan atau sosialisasi sangat penting bagi guru RB/KBIT Siti Khodijah.

Adapun target dalam pengabdian kepada masyarakat ini adalah: (a) Terjadi peningkatan pengetahuan guru tentang perkembangan anak dengan DDST di RB/KBIT Siti Khodijah. (b) Meningkatkan pengetahuan guru tentang gangguan atau penyimpangan perkembangan pada anak. (c) Meningkatkan pengetahuan dan ketrampilan guru dalam melakukan pemantauan perkembangan terhadap anak dengan metode DDST. (d) Terdeteksinya anak yang mengalami gangguan perkembangan. Sementara untuk luaran yang akan dicapai (b) Peningkatan pengetahuan guru tentang cara pemeriksaan perkembangan dengan DDST. (b) Peningkatan ketrampilan guru dalam melakukan deteksi dini perkembangan anak dengan menggunakan DDST. (c) Artikel Ilmiah yang terpublikasi.

\section{METODE KEGIATAN}

Pelaksanaan pengabdian masyarakat dengan judul Deteksi Dini Perkembangan Anak dengan DDST (Denver Development Screening Test) di RA/KBIT Siti Khodijah Slawi dilaksanakan pada hari Selasa, Tanggal 25 Februari 2020. Metode yang digunakan adalah diskusi dengan Guru Kelas tentang pemantauan pemeriksaan DDST pada anak serta interpretasinya. Pemeriksaan DDST pada anak secara langsung dan melakukan interpretasi yang akan disampaikan ke masing-masing orang tua siswa.

a. Jadwal Kegiatan

Kegiatan pengabdian ini telah dilaksanakan sesuai dengan jadwal dan rincian yang telah ditetapkan dan disepakati sebelumnya. Berikut merupakan rangkaian waktu dan kegiatan yang telah dilakukan pada hari Selasa, 25 Februari 2020.

Tabel 1. Jadwal Kegiatan

\begin{tabular}{cll}
\hline Waktu & \multicolumn{1}{c}{ Kegiatan } & \multicolumn{1}{c}{ Penanggung Jawab } \\
\hline 08.00-09.00 & $\begin{array}{l}\text { Sosialisasi pada guru kelas } \\
\text { tentang DDST }\end{array}$ & $\begin{array}{l}\text { Ita Nur Itsna } \\
\text { Jumrotun Ni' mah }\end{array}$ \\
09.00-12.00 & $\begin{array}{l}\text { Pemeriksaan DDST pada anak } \\
\text { Interpretasi pemeriksaan DDST } \\
\text { pada anak }\end{array}$ & $\begin{array}{c}\text { Anisa Oktiawati } \\
\text { Ramadhan Putra S }\end{array}$ \\
\hline
\end{tabular}


b. Presensi Kegiatan

Kegiatan pengabdian ini diikuti oleh dosen STIKes Bhakti Mandala Husada Slawi Program Studi D III Keperawatan. Jumlah anak yang di lakukan pemeriksaan DDST adalah 125 anak, dan jumlah guru yang diberikan sosialisasi ada 16 guru.

c. Foto Pelaksanaan Kegiatan

Berikut merupakan foto-foto kegiatan yang telah dilakukan:

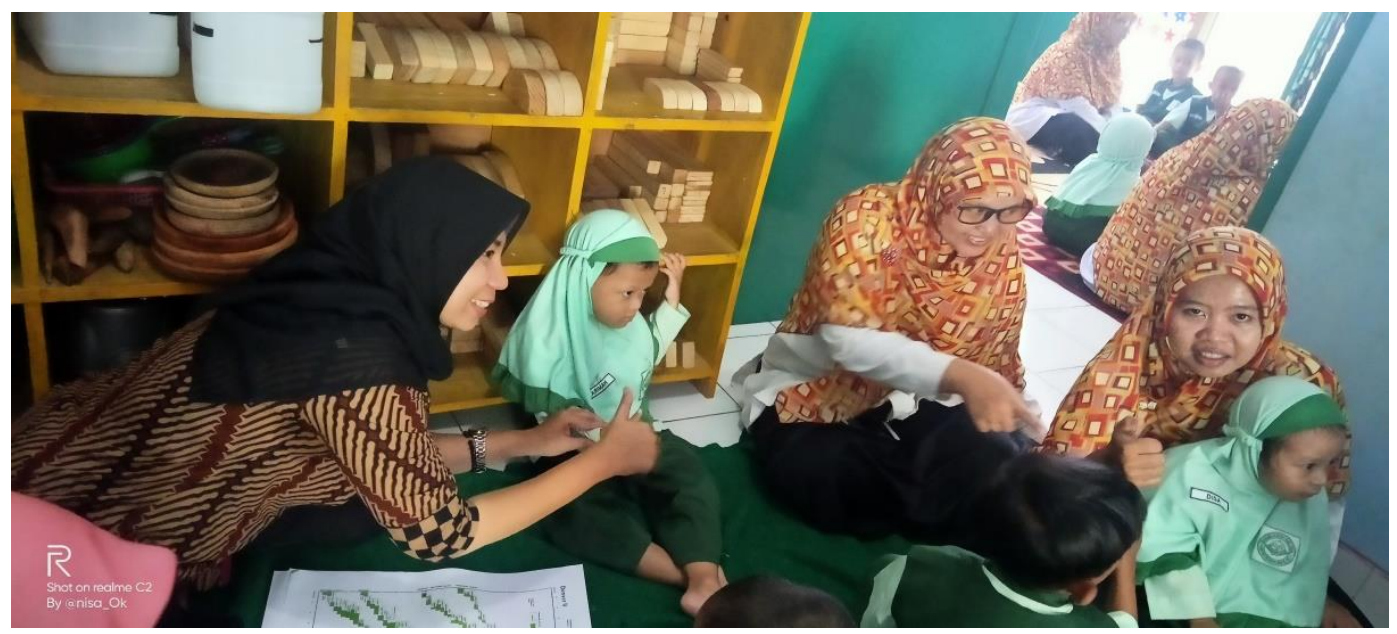

Gambar 1. Kegiatan Pemeriksaan DDST pada Anak

Pada Gambar 1. Ibu Anisa Oktiawati, melakukan pemeriksaan DDST pada anak dengan menyuruh mengacungkan ibu jari. Tujuannya agar supaya anak mampu menggunakan motorik halusnya.

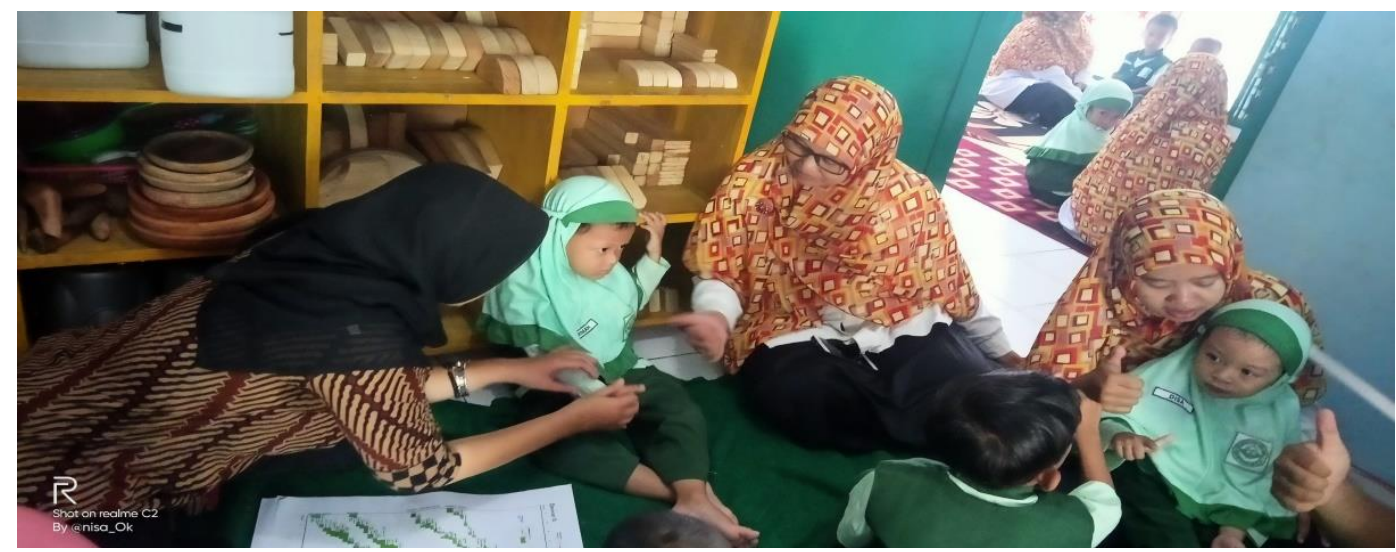

Gambar 2. Sosialisasi Pemeriksaan DDST Pada Guru

Pada Gambar 2. Ibu Anisa Oktiawati, melakukan sosialisasi pemeriksaan DDST pada guru supaya guru mampu melakukan secara mandiri untuk melakukan deteksi dini perkembangan sesuai dengan tahap perkembangan anak. 


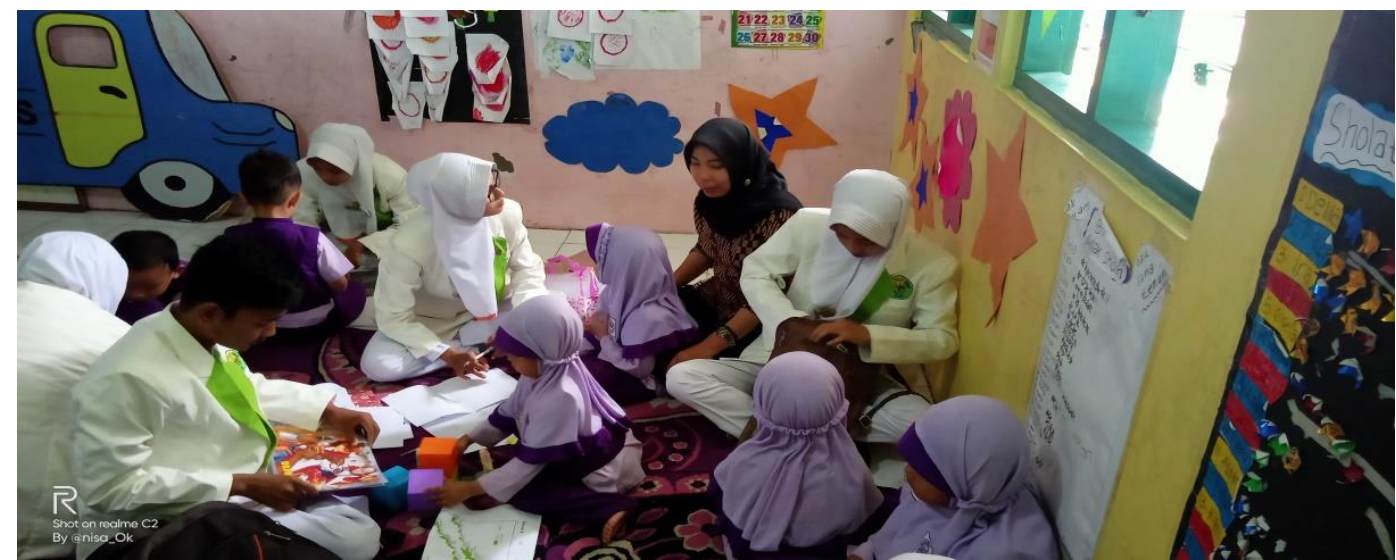

Gambar 3. Kegiatan Pemeriksaan DDST pada Anak

Pada Gambar 3. Ibu Anisa Oktiawati, melakukan pemeriksaan DDST pada anak dengan didampingi mahasiswa. Yaitu sedang menjelaskan bagaimana tahapan mulai dari awal sampai akhir dalam pelaksanaan DDST.

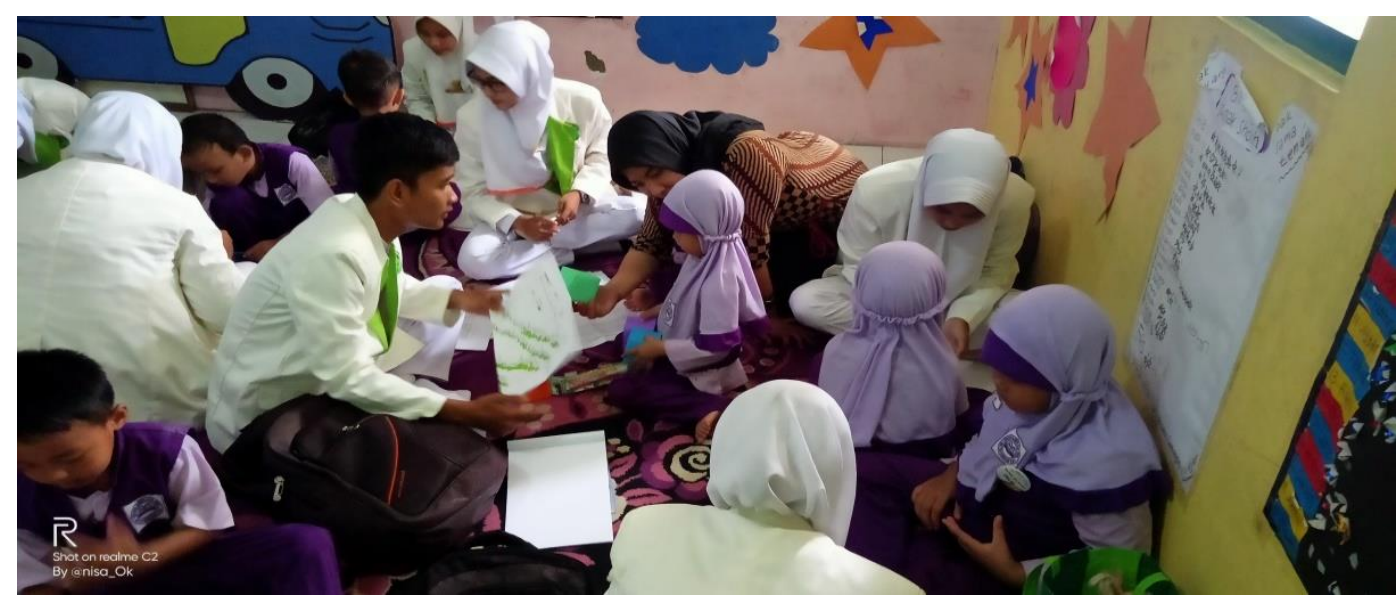

Gambar 4. Kegiatan Pemeriksaan DDST pada Anak

Pada Gambar 4. Ibu Anisa Oktiawati, melakukan pemeriksaan DDST pada anak dengan bertanya nama binatang yang berada pada lembar DDST.

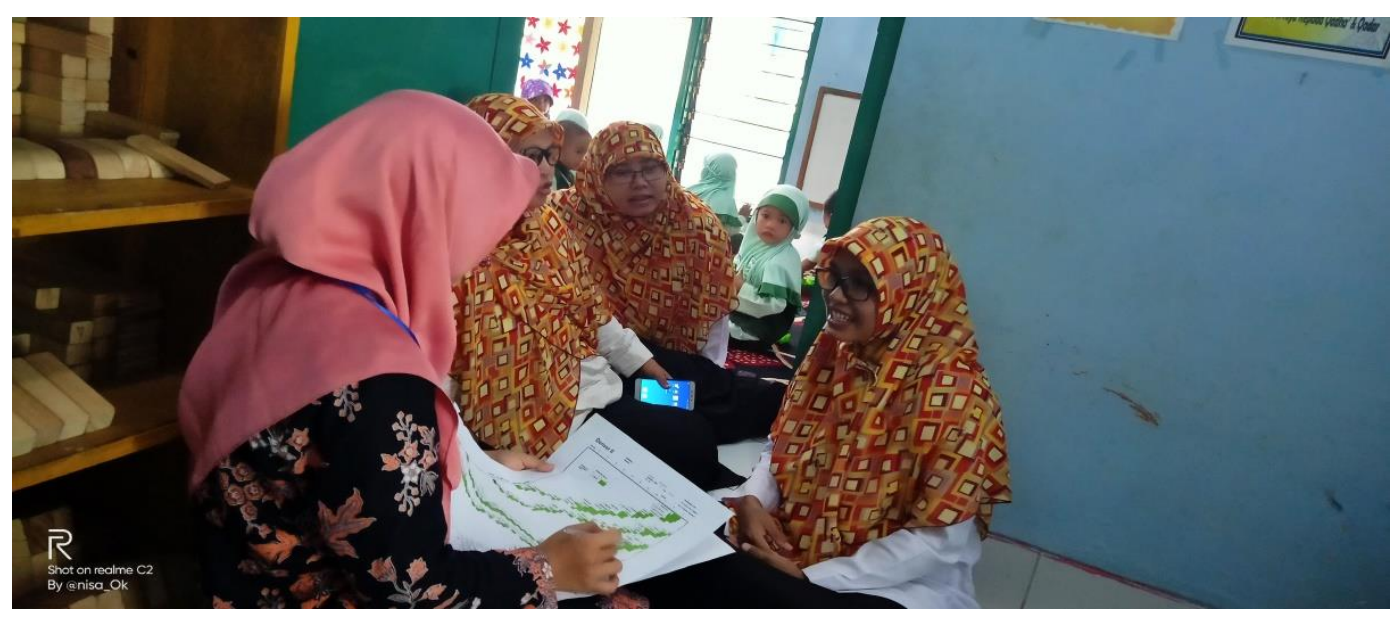

Gambar 5. Sosialisasi Pemeriksaan DDST pada Guru 
Pada Gambar 5. Ibu Ita Nur Itsna, melakukan sosialisasi pemeriksaan DDST pada guru menjelaskan bagaimana cara melakukan pemeriksaan sesuai dengan usia anak.

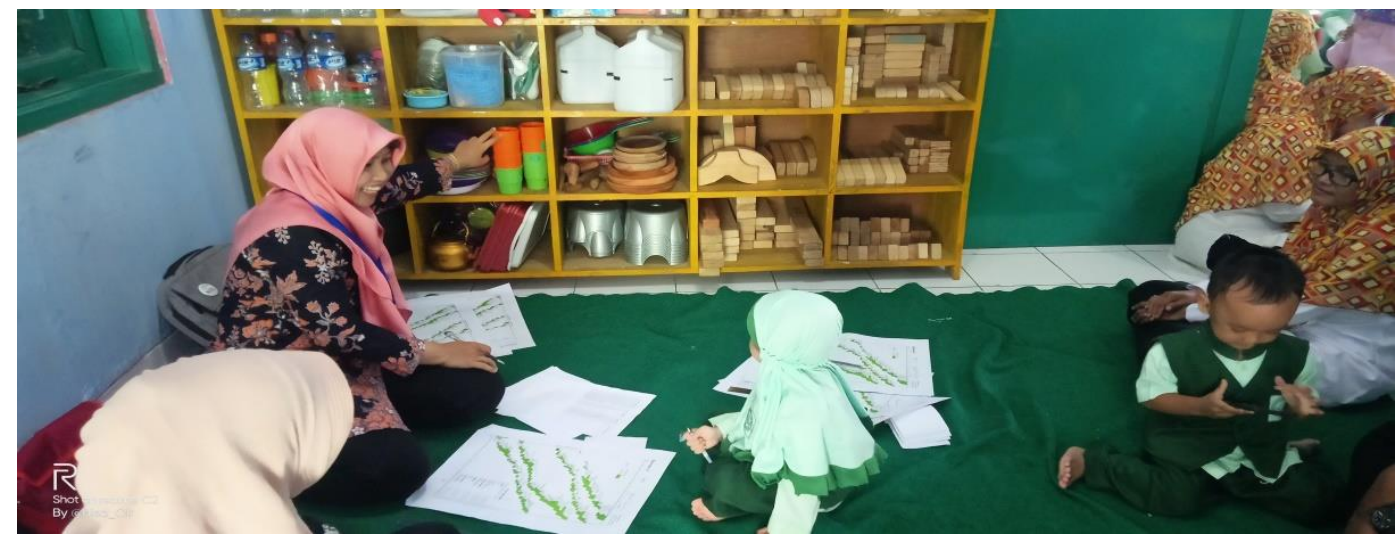

Gambar 6. Melakukan Pemeriksaan DDST pada Anak

Pada Gambar 6. Ibu Ita Nur Itsna, sedang Melakukan Pemeriksaan DDST pada Anak yaitu dengan bertanya kepada anak jenis-jenis warna yang berada di sekitar.

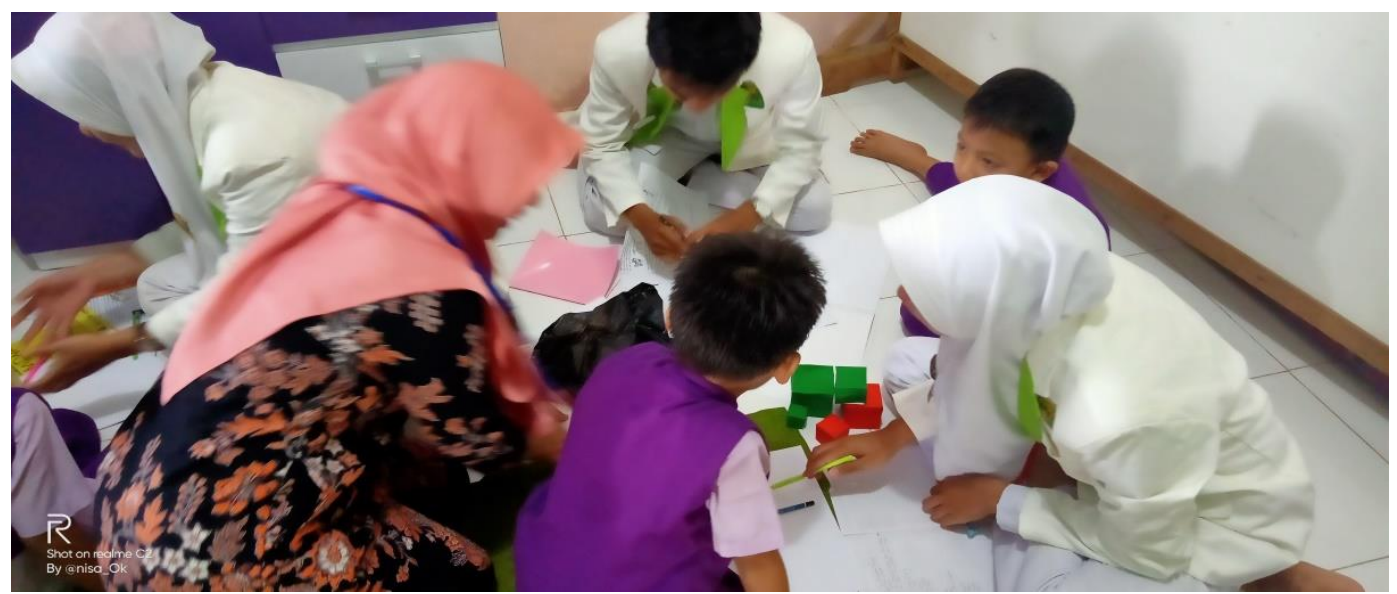

Gambar 7. Pemeriksaan DDST pada Anak dibantu oleh Mahasiswa

Pada Gambar 7. Ibu Ita Nur Itsna, sedang Melakukan Pemeriksaan DDST pada Anak dibantu oleh mahasiswa yaitu menanyakan macam-macam bentuk benda yang berada di sekitar anak. 


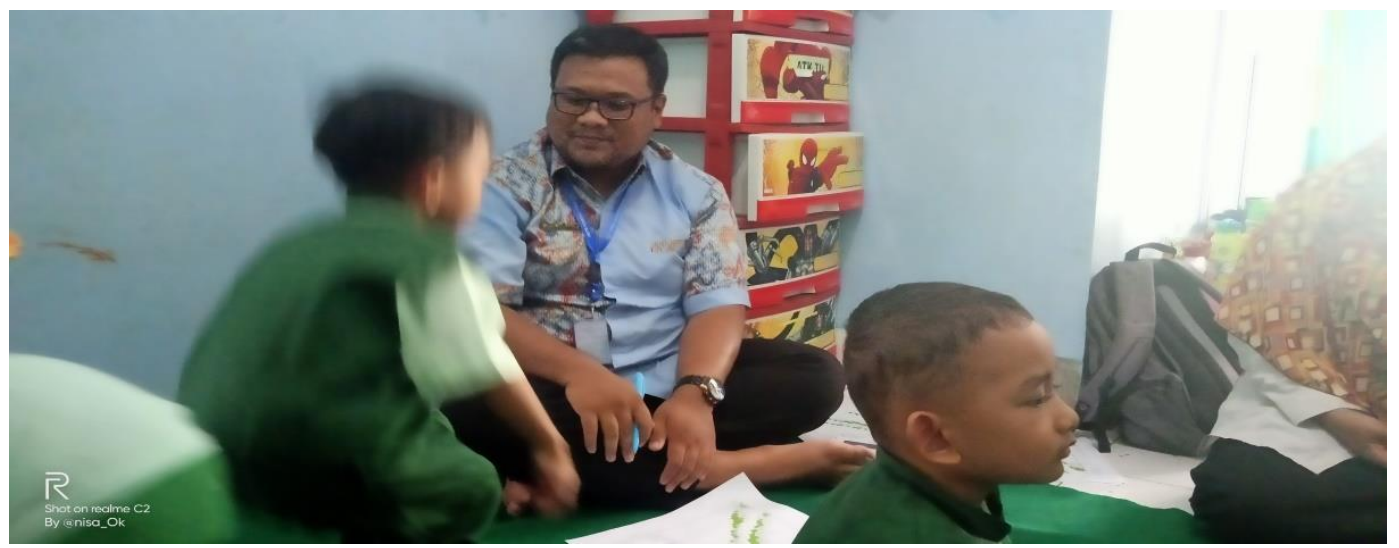

Gambar 8. Pemeriksaan DDST Pada Anak Yaitu dengan Cara Berdiri Satu Kaki

Pada Gambar 8. Bapak Ramadhan, sedang Melakukan Pemeriksaan DDST pada Anak yaitu dengan cara berdiri satu kaki. Hal tersebut digunakan untuk mengetahui motorik kasar berjalan atau tidak.

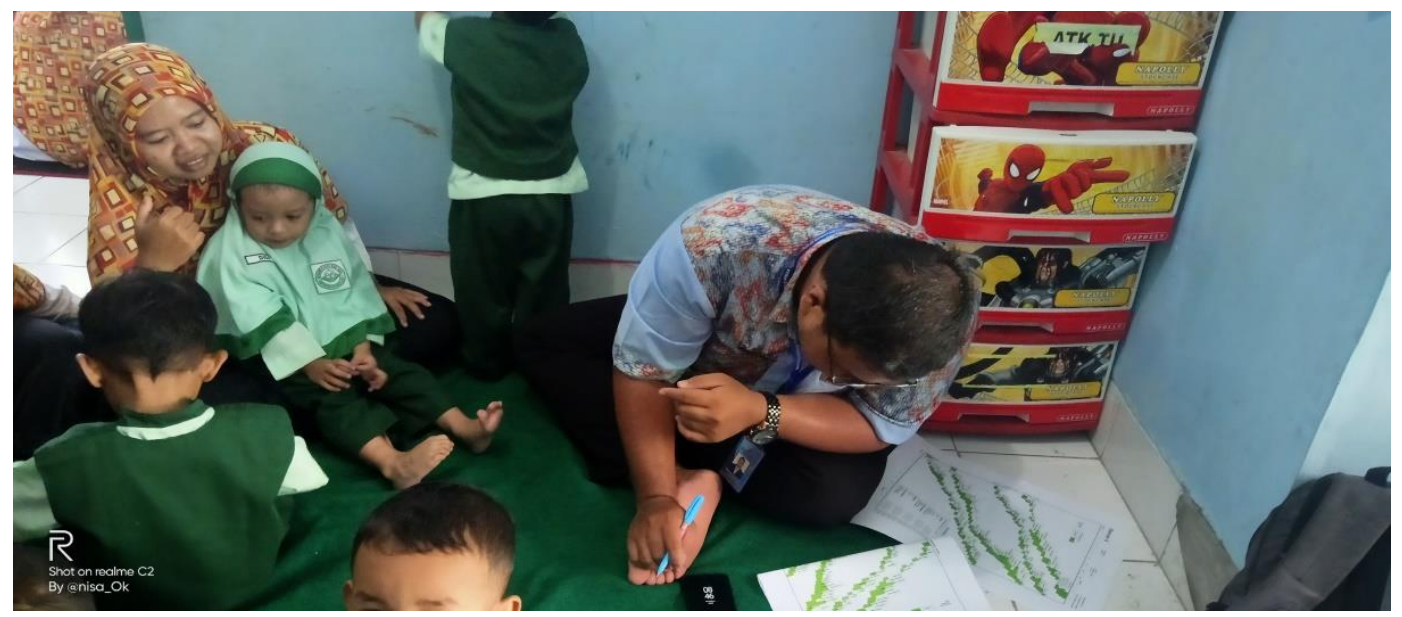

Gambar 9. Memberikan Informasi Kepada Guru Kegiatan yang Sesuai dengan Usia Anak

Pada Gambar 9. Bapak Ramadhan, melakukan sosialisasi pemeriksaan DDST pada guru yaitu memberikan informasi tentang kegiatan yang sesuai dengan usia anak.

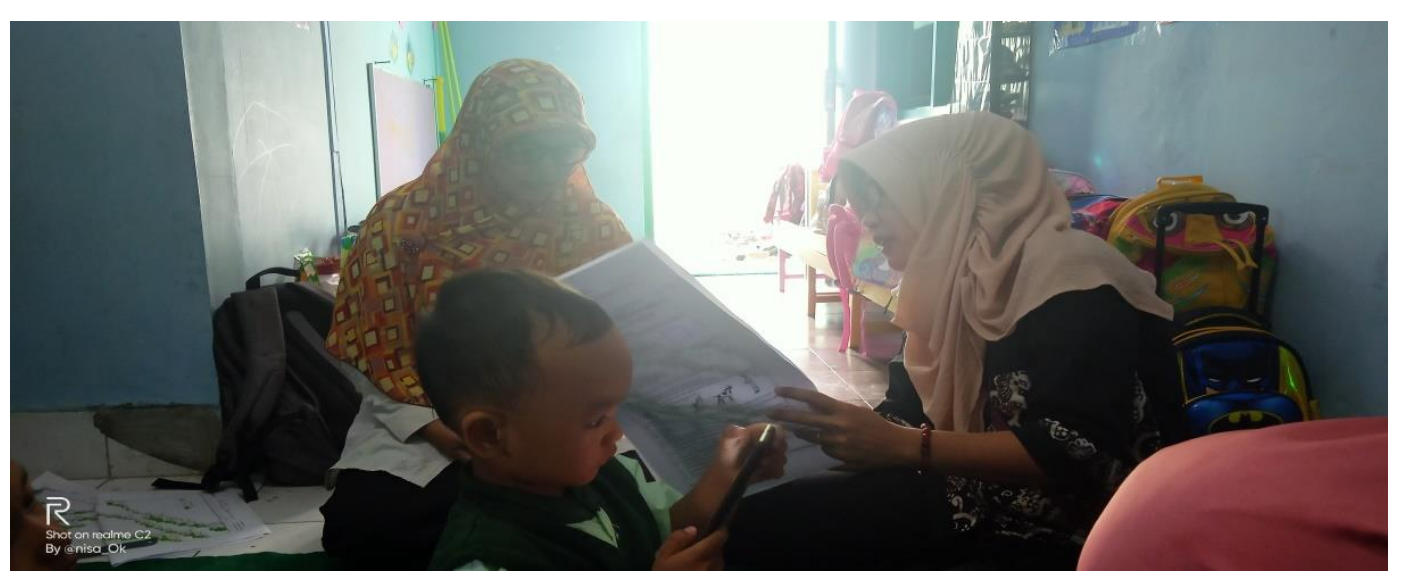

Gambar 10. Menunjukkan Hasil Pemeriksaan Anak Kepada Guru 
Pada Gambar 10. Ibu Jumrotun Ni'mah, melakukan sosialisasi pemeriksaan DDST pada guru yaitu dengan menunjukkan hasil pemeriksaan anak kepada guru.

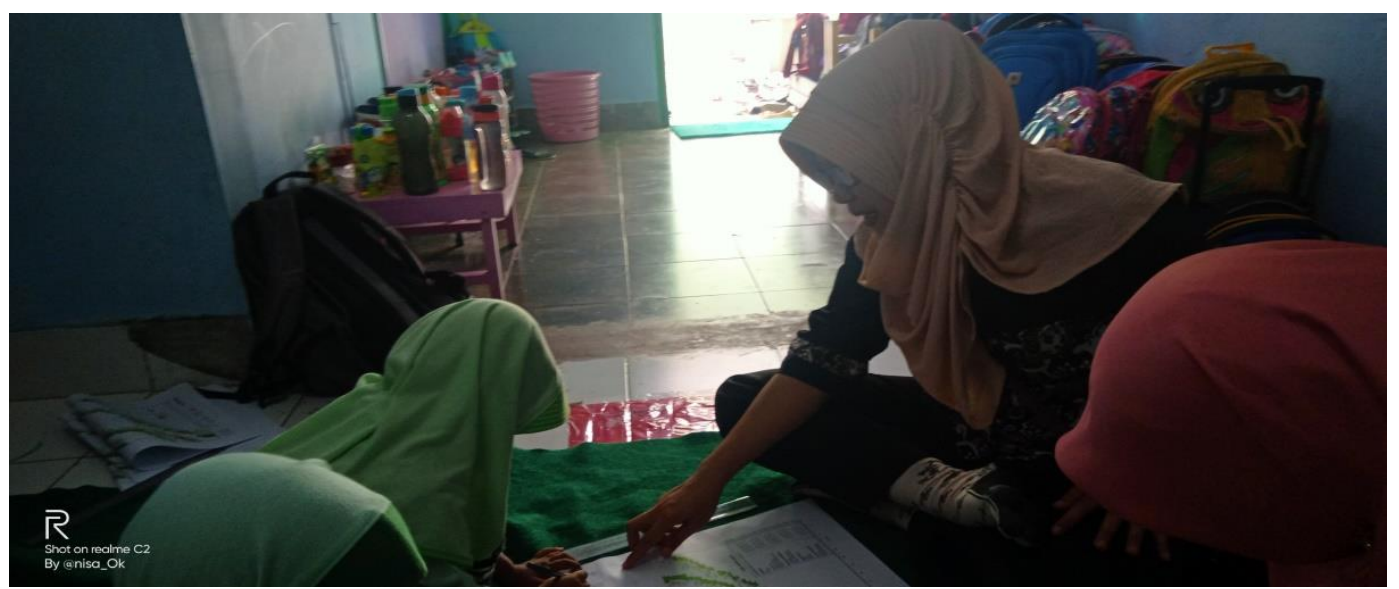

Gambar 11. Melakukan Pemeriksaan DDST pada Anak Sambil Menggambar Pola Tertentu

Pada Gambar 11. Ibu Jumrotun Ni'mah, sedang Melakukan Pemeriksaan DDST pada anak yaitu dengan menyuruh anak menggambarkan bentuk benda seperi lingkaran, bulat dan garis lurus.

\section{HASIL PEMBAHASAN DAN DAMPAK}

Hasil Pemeriksaan DDST yang dilakukan pada 125 anak didapatkan hasil keseluruhan adalah 121 anak (96,8\%) dinyatakan normal, 3 anak $(2,4 \%)$ mengalami perkembangan suspect dan 1 anak $(0,8 \%)$ tidak dapat dites. Tumbuh kembang anak secara menyeluruh dapat diamati dari gerak kasar (motorik kasar), gerak halus (motorik halus), kemampuan bahasa, bersosialisasi, kemandirian. Menurut Soetjiningsih (2005), ada 4 parameter untuk menilai perkembangan anak yaitu personal sosial, motorik halus, bahasa dan motorik kasar. Perkembangan anak yang normal dipengaruhi adanya stimulasi yang dilakukan oleh orang tua. Menurut Soetjiningsih dan Ranuh (2013), anak akan mendapat stimulasi yang terarah dan teraruh lebih cepat berkembang dari pada anak yang tidak mendapat stimulasi dari siapapun. Stimulasi mental (asah) dapat menunjang perkembangan mental psikososial anak yang meliputi kecerdasan, kemandirian, kreativitas anak, kepribadian, dan produktifitas. Evandrou, et al (2016) menyebutkan bahwa dukungan orang tua sangat penting dalam tahap perkembangan anak, hal tersebut dapat merangsang perkembangan otak anak. Dukungan orang tua dapat berupa mengajak bicara anak, melakukan permainan kecil yang merangsang motorik anak. Berbagai macam dan cara untuk merangsang perkembangan anak sesuai dengan usianya yaitu dapat berupa 
menulis, bersosialisasi dengan orang lain, dan dukungan kognitif (Aram dan Besser-Biron, 2016).

Interpretasi dari nilai DDST pada tiap aspek perkembangan, pada pengabdian masyarakat ini menunjukkan pada motorik halus, bahasa dan motorik kasar terdapat klasifikasi advanced (lebih) artinya anak melewati uji coba yang terletak di kanan garis usia sehingga dinyatakan perkembangan anak lebih dari kemampuan anak yang seusianya. Anak dengan hasil perkembangan sesuai dapat melanjutkan stimulasi sesuai dengan tahapan perkembanganya, anak dengan hasil meragukan (suspect) dapat melakukan uji ulang dalam 1-2 minggu untuk menghilangkan faktor sesaat (takut, lelah, sakit, tidak nyaman), anak dengan perkembangan tidak teruji melakukan ulang pemeriksaan 1-2 minggu (Soetjiningsih dan Ranuh, 2012). Yamaguchi et al (2019) menyebutkan bahwa pemeriksaan motorik halus dan kasar harus mempertimbangkan aspek suasana hati dan kondisi fisik dari anak.

Orang tua dapat melatih kemandirian anak, seperti mengajari anak mengambil dan menyimpan mainan, baju dan lain-lain yang anak miliknya. Anak perlu dibantu dalam melakukan kegiatannya, namun sedikit demi sedikit dikurangi bantuan dan biarkan anak melakukannya sendiri, anak juga diminta membantu menyiapkan meja makan dan melakukan pekerjaan ringan di sekitar rumah, atau mengajak anak untuk bermain dengan teman sebayanya (Kementerian Kesehatan RI, 2010 dalam Rosita dan Norazizah, 2012). Kemandirian anak tidak bisa terpisah dari bantuan orang tua, menyiapkan alat-alat yang digunakan setiap harinya seperti alat makan, alat untuk mandi, berganti baju. (Amini, 2017). Menurut Astuti (2011) mengatakan bahwa apabila ada balita yang tidak mau mencoba melakukan hal-hal yang mengasah kemandiriannya, sebaiknya menggunakan cara yang lembut dan membuat kegiatan itu sebagai aktivitas yang menyenangkan, dengan membawa anak ke lingkungan teman-teman sebaya juga bermanfaaat untuk menantang anak melakukan hal-hal yang sudah mampu dilakukan teman-temannya, orang tua bisa memstimulus anak dengan menyontohkan apa yang dilakukan temannya (Rosita dan Norazizah, 2015).

\section{SIMPULAN DAN SARAN}

Hasil Pemeriksaan DDST yang dilakukan pada 125 anak didapatkan hasil keseluruhan adalah 121 anak $(96,8 \%)$ dinyatakan normal, 3 anak (2,4\%) mengalami perkembangan suspect dan 1 anak $(0,8 \%)$ tidak dapat dites. Dengan adanya guru RB/KB IT yang terlatih 
diharapkan kegiatan deteksi dini perkembangan anak dapat berjalan secara rutin sehingga perkembangan anak menjadi tanggung jawab bersama antara orang tua dan guru. Guru diharapkan dapat memperhatikan perkembangan anak didiknya dengan cara menstimulasi pada 4 aspek perkembangan, yaitu personal sosial, adaptif-motorik halus, bahasa, dan motorik kasar agar perkembangan anak dapat mencapai optimal.

\section{DAFTAR PUSTAKA}

Astuti, N, W. (2015). Gambaran Perkembangan Balita di Posyandu Anggrek Ponggok I Desa Trimulyo Jetis Bantul Yogyakarta. STIKES Jenderal Achmad Yani Yogyakarta.

Amini, M. (2017). Parental Involvement in Improving Independence in Early Childhood. https://doi.org/10.2991/icece-17.2018.48

Aram, D., \& Besser-Biron, S. (2016). Parents' support during different writing tasks: a comparison between parents of precocious readers, preschoolers, and school-age children. Reading and Writing, 30(2), 363-386. doi:10.1007/s11145-016-9680-6.

Chamidah, A. N. (2009). Deteksi Dini Jurnal Endurance 3(2) Juni 2018 (367-374) Kopertis Wilayah X 374 Gangguan Pertumbuhan dan Perkembangan Anak', Jurnal Pendidikan Khusus, 5(9), pp. 83-93.

Evandrou, M., Falkingham, J., Gomez-Leon, M., \& Vlachantoni, A. (2016). Intergenerational flows of support between parents and adult children in Britain. Ageing and Society, 38(02), 321-351. doi:10.1017/s0144686x16001057

Soetjiningsih. (2005). Tumbuh Kembang Anak. Jakarta: Penerbit EGC

Soetjiningsih \& Ranuh. (2012). Tumbuh Kembang Anak. Edisi 2. Jakarta: EGC.

Rosita, D dan Norazizah, Y. (2012). Studi Deskriptif Perkembangan Balita Usia 12-24 Bulan dengan Metode DDST II di Desa Pancur Kecamatan Mayong Kabupaten Jepara. Jurnal Kesehatan dan Budaya HIKMAH, 8(1).

Yamaguchi, B., Silva, A. Z., Araujo, L. B., Guimarães, A. T. B., \& Israel, V. L. (2019). Psychomotor evaluation of children attending Child Education Centers in the south of Brazil. Early Child Development and Care, 1-8. doi:10.1080/03004430.2019.1672165 